\title{
SCIENTISTS IN THE PUBLIC SERVICE
}

\author{
SPECIAL PROMOTIONS
}

GPECIAL posts have been created in the Civil Service as in previous years under provisions included in the White Paper on the Scientific Civil Service (Cmd. 6679,1945 ) to provide for the promotion of individual research workers of exceptional merit. The promotions were effective from July 1, and include the following.

\section{Deputy Chief Scientific Officer}

Mr. R. BenJamin joined the Admiralty Signal Establishment in 1944. During the following years his many contributions to radio and radar research and development were notable for their remarkable insight and brilliant execution. Promotion was rapid and he became a special merit senior principal scientific officer, in 1955, at the age of 32 . By that time he was already established as an international authority on the theory, design and use of circuits in the video and pulse fields. His practical application of this knowledge to the processing and display of information, together with a major contribution to the concept of the accompanying radar, have borne fruit in the latest naval 3-D air-defence system which has been demonstrated with such conspicuous success. In addition to a continuing concern with advanced radar systems since 1955, Mr. Benjamin has been exploring new techniques of automation and computation to be applied to data processing and weapon control in virtually the whole field of naval warfare.

Mr. L. G. Carpenter, head of the Metallurgy Department, Royal Aircraft Establishment, joined the Establishment as head of the Research Section of the Instrument Department in 1937, and in 1940 was responsible for development of the first gyro-stabilized bomb site to go into Royal Air Force use. In 1940 he was transferred to the charge of the Research Section of Armaments Department concerned with bomb fuzes, bomb ballistics and the air-to-ground rocket weapon. In 1944, he was appointed head of the General Armaments Division and in 1946 head of the High-Temperature Materials Group in the Metallurgy Department. This group was the first (1947) in the United Kingdom to prepare titanium in a pure state and determine its properties. He has guided research on metal fatigue, properties of materials at high temperatures, the use of graphite for the hot parts of rockets and as a fuel container for nuclear reactors and the study of gas/solid reactions. His recent personal work has been concerned with the absorption of oxygen and nitrogen by hot titanium and the oxidation of gold. $\mathrm{He}$ is at present engaged on the reaction of rarified beams of nitrogen with solid surfaces and the required vacuum techniques.

Dr. L. Essen, of the National Physical Laboratory, is internationally well known for his pioneer work on precise frequency standards for accurate measure- ments of frequency and time-interval. His first major contribution, the Essen quartz-ring oscillator, proved greatly superior to any previous frequency standard and to any mechanical clock for precise time-keeping in observatories and standard laboratories. More recently he was responsible for introducing the cæsium atomic beam resonator as a natural standard with a frequency stability and reproducibility of 1 part in $10^{10}$. With his co-workers in Britain and in the United States he has used it to calibrate quartz clocks and monitor standard frequency transmissions, thereby establishing invaluable data on the performance of quartz clocks and different cæsium standards, the propagation of radio signals, variations of the Earth's rate of rotation and the value of the second of (ephemeris) time in terms of the cæsium standard. His determination in 1947 and 1950 of the velocity of propagation of microwave radiation revealed the fact, since confirmed by other observers in the microwave and optical regions, that the previously accepted value of the velocity of light was too low by 1 part in 20,000 . His work as an experimental physicist has been nationally and internationally recognized by several awards and he was recently elected a Fellow of the Royal Society.

Dr. C. Trmms joined the scientific staff of the Metrology Division at the National Physical Laboratory in 1936. There he worked with Dr. G. A. Tomlinson, whose work on the standards of accuracy of gear-cutting machinery he has since continued and developed. This work played a large part in the marked improvement effected during the Second World War in the accuracy and reliability of naval and marine reduction gear drives. $\mathrm{He}$ is now a national authority on all aspects of gear metrology, and recently was invited to give the annual Viscount Nuffield Lecture to the Institution of Production Engineers on this subject. He has also carried out fundamental work in the measurement and assessment of surface finish, and has been largely responsible for the development of the branch of precision engineering measurement referred to as dynamic metrology. Dr. Timms became head of the Mechanisms, Metrology and Noise Control Division of the National Engineering Laboratory in 1950 , and is now applying his knowledge and experience to improvement of the performance of machine tools, particularly in the application of precision circular diffraction gratings to measurement and correction of errors.

\section{Senior Principal Scientific Officer}

DR. R. N. Cox of the Armament Research and Development Establishment has a wide background of research in experimental and theoretical fluid dynamies and is an expert in the field of hypersonics research. 


\section{Nc. 4747 October $22,1960 \quad$ N A T U R E}

DR. R. G. HopkINSON is in charge of that part of the Building Research Station research programme which deals with the lighting of buildings; his particular research interest is the psycho-physics of illumination in relation to design for daylighting and artificial lighting. Good lighting has an important influence on building design, and Dr. Hopkinson's work has contributed greatly to the definition of the quality of lighting on a metrical basis.

Mr. D. G. KING-HELE of the Guided Weapon Department, Royal Aircraft Establishment, is a versatile mathematician, whose work on satellite orbits is now internationally known.

Dr. D. McLean of the Metallurgy Division, National Physical Laboratory, is engaged on the investigation of dislocation structure in iron and iron alloys using the thin-film technique in the electron microscope.

Mr. E. C. MASkell of the Aerodynamics Department, Royal Aircraft Establishment, is an outstanding aerodynamics worker, particularly in the field of slender wings and jet flaps.

Mr. W. R. Piggots joined the Department of Scientific and Industrial Research in September 1939. After an early association with Sir Edward Appleton in certain special radio projects during the War, he joined the staff of the Radio Research Station and began his studies of the ionosphere for which he is so well known. Mr. Piggott has made an intensive investigation of the absorption of radio waves by the ionosphere, and pursued this and related topics in great detail during the International Geophysical Year: in the latter respect he has made valuable analyses of the observations made at Halley Bay by members of the Royal Society Expedition. His outstanding contribution to knowledge of the upper atmosphere is demonstrated by the numerous papers he has published, including a special report issued by the Department concerning the design of aerials to take the best advantage of the ionosphere for longdistance transmission.

Mr. L. P. Sмrтt has been head of that section of the Meteorological Office which specializes in meeting the requirements of agriculture and horticulture sinco 1949. His success in this form of operational research has been noteworthy, and he has made many practical and easily assimilated contributions to good husbandry. His studies have included relationships between weather conditions and the spread of blights and diseases of plants and animals.

DR. N. URI joined the Research Establishment and Experimental Factory, Aberdeen, of the Ministry of Agriculture, Fisheries and Food in 1954 as a Senior Government Research Fellow, and was established as a principal scientific officer in 1956. The applied objectives of his work have been the prevention of deterioration by oxidative rancidity in food, particularly foods with low water content produced by freezedrying. He has developed a theory on the effect of the polarity of the environment on trace metal catalysis in relation to the onset and speed of oxidative rancidity in fats. He has devised a new method of testing the stability of fats based on metal catalysis. $\mathrm{He}$ has also investigated the anti-oxidant properties of naturally occurring substances such as quercetin and the synthesis of new anti-oxidants.

Mr. W. WAtT of the Metallurgy Department, Royal Aircraft Establishment, is a research worker in the field of high-temperature materials, especially ceramics and interstitial graphite.

Similar promotions have been made by :

\section{(I) Agricultural Research Council : Senior Principal Scientific Officer}

Dr. R. A. Beatry of the Unit of Animal Genetics, Edinburgh, is engaged on work in the common ground between genetics, embryology and reproductive physiology.

DR. R. M. C. Dawson of the Biochemistry Department, Institute of Animal Physiology, Babraham, Cambridge, works on phospholipids and their metabolism.

DR. R. F. GLASCOCK is head of the Department of Radiobiochemistry at the National Institute for Research in Dairying, Reading, and has specialized in the application of the isotopic tracer technique to biochemical problems.

Dr. C. G. Johnson is a member of the Entomology Department of the Rothamsted Experimental Station, Harpenden, Herts. He is best known for his work on the aerial dispersal of insects.

\section{(2) U.K. Atomic Energy Authority: Senior Principal Scientific Officer}

Dr. T. E. Cranshaw has worked at Harwell for ten years. During the first eight years he worked on extensive air showers produced by high-energy cosmic rays. In 1954 he designed and built the apparatus at Culham Airfield which was the first to use the principle of covering a large area by a lattice of identical units, and with which many properties of air showers were investigated. In 1959 , Dr. Cranshaw performed an experiment to measure a possible difference between the charges of the proton and the electron, which was shown to be smaller than one part in $10^{20}$. More recently he has worked on the Mössbauer effect and its application to relativistic frequency shifts.

Mr. R. D. LowDE, during his thirteen years at the Atomic Energy Research Establishment, Harwell, has been in particular an exponent of neutron inelastic scattering techniques as a means of studying the solid state. He was the first to demonstrate the crystallographic phenomena that are the basis of the modern neutron-diffraction methods of investigating lattice vibrations and the dynamies of spin systems in magnetic substances. In recent years he has carried through a series of investigations in the theory and practice of these methods; the principal results have been the finding of effects due to 'spin waves' in metallic iron and due to magnetic 'critical phenomena' near the Curie temperature of the same material. In addition to his work in neutronics and magnetism, he has published researches in electronics and crystallography, and many papers on scientific instruments and methods.

\section{(3) Nature Conservancy : Senior Principal Scientific Officer}

MR. M. V. BrIAN is officer in charge of the Furzebrook Research Station of the Nature Conservancy. $\mathrm{He}$ is well known for his contributions on social insect populations. 